\title{
COMUNIDADE NIKKEI DE PARACATU-MG E SUAS EXPERIÊNCIAS DE DESENVOLVIMENTO NO CONTEXTO DO PRODECER ${ }^{1}$ NIKKEI COMMUNITY OF PARACATU, MG AND ITS DEVELOPMENT EXPERIENCES IN THE CONTEXT OF PRODECER
}

\author{
Nanahira de Rabelo e Sant'Anna ${ }^{2}$
}

Resumo: O artigo apresenta resumo de tese sobre outras possíveis leituras e perspectivas sobre processos de desenvolvimento a partir de relatos orais a respeito da trajetória da comunidade nikkei de Paracatu-MG, composta de pessoas e grupos que migraram para o Município na segunda metade do Século XX, no contexto da abertura de novas fronteiras agrícolas no Cerrado, proporcionada por programas como o PRODECER. Um entendimento sobre processos de desenvolvimento como experiências que emergem de subjetividades em sua diversidade e complexidade, agrupadas nas dimensões de migração, trabalho, educação, comunidade e cultura, foi obtido com a aplicação de conceitos e abordagens dos estudos pós-coloniais na análise das aspirações, valores e expectativas de desenvolvimento dos nikkeis ao longo de suas trajetórias de vida.

Palavras-chave: Comunidade Nikkei; PRODECER; Desenvolvimento; Pós-Colonialismo; Relações Brasil-Japão.

\begin{abstract}
The article presents a summary of a thesis about other possible interpretations and perspectives on development processes from oral reports on the history of the Nikkei community from Paracatu-MG, composed of people and groups that migrated to the Municipality in the second half of the 20th century, in the context of the opening of new agricultural frontiers in Cerrado, provided by programs such as PRODECER. An understanding of development processes as experiences that emerge from subjectivities in their diversity and complexity, grouped in the dimensions of migration, work, education, community and culture, was achieved through the application of concepts and approaches from the post-colonial studies in the analysis of the

$1 \quad$ Article received and accepted in 2019 .

2 Doutora em Desenvolvimento, Sociedade e Cooperação Internacional pela Universidade de Brasília (UnB), Brasília, DF; nanahira.rabelo@gmail.com; (ORCID iD: http://orcid.org/0000-0002-4072-7250).
\end{abstract}


Nikkei's development aspirations, values and expectations throughout their life trajectories.

Keywords: Nikkei community; PRODECER; Development; Post-Colonialism; Brazil-Japan relations.

\section{Introdução}

A comunidade de origem japonesa residente no Brasil celebrou 100 anos da imigração em 2008, e muito já foi publicado a respeito da história dos imigrantes e seus descendentes em várias localidades do território brasileiro. $\mathrm{O}$ mesmo pode ser aplicado à história do município de Paracatu, localizado na porção noroeste do estado de Minas Gerais, que completou 220 anos em 2018. Merece investigação mais aprofundada a trajetória da comunidade nikkei residente no Município, composta de pessoas cujas histórias de vida indicam outras possibilidades em matéria de pensamento e ação na temática do desenvolvimento, para além de fatores ou determinantes como crescimento econômico, distribuição de renda, saúde, educação, longevidade e preservação ambiental, considerando a consolidação dessa comunidade em Paracatu no contexto do Programa Nipo-Brasileiro para o Desenvolvimento dos Cerrados - PRODECER, na segunda metade do Século XX.

A presença de uma comunidade de origem nipônica em Paracatu, município que tem sua história vinculada ao ciclo do ouro do Brasil colônia, muito se deve à migração de descendentes de japoneses oriundos de municípios das regiões Sul e Sudeste do Brasil, parte considerável dos quais participaram do referido Programa como colonos agrícolas. O solo do Município é explorado para a atividade mineradora desde o Século XVIII, enquanto que atividade agrícola, iniciada no Século XIX, passou a ser tecnificada e implantada em larga escala a partir da segunda metade do Século XX, o que foi estimulado por planos econômicos e programas governamentais como o PRODECER (OLIVEIRA MELLO, 1994; 2007).

Criado em 1974, mediante comunicado conjunto assinado pelo Primeiro-Ministro do Japão, Kakuei Tanaka, e pelo Presidente do Brasil, Ernesto Geisel, e implantado de 1979 a 2001, em três etapas, o PRODECER tinha por objetivos estimular o aumento da oferta de alimentos no mundo e contribuir para o desenvolvimento na região dos Cerrados, bioma que ocupa aproximadamente $25 \%$ do território brasileiro, equivalente a cerca de 5,5 vezes a área do Japão. Paracatu, que possui vegetação nativa típica do Cerrado, consiste na localidade em que o Programa teve início, que abrigou a maioria de projetos realizados, e que recebeu o maior número de produtores assentados (BRASIL; JICA, 2002) ${ }^{3}$.

3 Segundo informações de relatório publicado conjuntamente pelo Ministério da Agricultura, Pecuária e Abastecimento do Brasil - MAPA - e a Agência de Cooperação Internacional do Japão - JICA - em 2002, em Paracatu foram realizados cinco dos 21 projetos do PRODECER e assentados 147 do total de 717 produtores. Em 2002, permaneciam residindo nas regiões de Paracatu onde os projetos foram 
Também são inúmeros os estudos sobre características e impactos da implantação e execução do PRODECER, realizados por autores de diversas áreas das Ciências Humanas e Sociais. Tais análises podem ser agrupadas em duas linhas, uma das quais compreendendo estudos que enfocam as repercussões positivas do Programa para as relações entre Brasil e Japão, para a oferta de alimentos no mundo e para o desenvolvimento econômico e a modernização agrícola do País. Em geral, esse primeiro grupo embasa suas análises em fontes escritas, geralmente emanadas por instituições governamentais e empresariais de Brasil e Japão, a exemplo de acordos bilaterais, relatórios, discursos e outros documentos oficiais sobre o PRODECER, ou seja, ampara-se na história oficial sobre o Programa.

A segunda vertente agrupa pesquisas que criticam repercussões do PRODECER na forma de concentração de terras, êxodo rural, conflitos sociais, degradação ambiental, endividamentos, falências, entre outras. Os estudos desse segundo grupo, além de considerar fontes escritas, incorporam relatos orais de autoridades governamentais e de produtores e trabalhadores rurais participantes ou não do Programa, assim como fotografias, mapas e outras fontes não escritas.

Em diálogos com japoneses e descendentes que residem em Paracatu, em etapa preliminar e exploratória da pesquisa, tais pessoas apresentaram-me fatos e impressões que dificilmente poderiam ser enquadradas em apenas uma ou outra das duas polaridades apresentadas na literatura, face à sua diversidade e complexidade. Foi possível perceber dinâmicas sobre temas aparentemente distintos, duais e mesmo contraditórios, alguns deles apresentados simultaneamente ao longo de uma mesma narrativa de história de vida. Deles emergiu a origem desta pesquisa: reler as experiências de desenvolvimento no quadro histórico do PRODECER passando mais ao largo de dicotomias presentes na literatura nacional e internacional sobre o Programa. Não se trata de uma proposta de estudo acrítico, mas de uma curiosidade genuína por conhecer histórias de vida em que emergem questões de desenvolvimento em suas complexas relações com experiências singulares daqueles sujeitos históricos presentes na região nos momentos de implantação do Programa.

Portanto, sem pender para uma ou outra das duas linhas, e sem desconsiderar as contribuições desses estudos para o entendimento dos processos que caracterizaram a cooperação entre Brasil e Japão para o desenvolvimento pela modernização agrícola dos Cerrados, pretendi seguir uma terceira via, um outro caminho, afastado de dualismos, binarismos e polarizações, que não se concentre em celebrar ou em denunciar o PRODECER, apresentar acertos ou erros do Programa. Sigo a rota da oralidade para abordar histórias de vida de migrantes no contexto de processos de desenvolvimento, considerando que relatos orais são capazes de indicar novas possibilidades para se pensar o desenvolvimento.

realizados 97 do total de 466 produtores assentados em todas as demais localidades (BRASIL; JICA, 2002). 
Face à diversidade e complexidade presente nos relatos dos nikkeis de Paracatu obtidos no decorrer desta pesquisa, inclusive sobre questões econômicas, sociais e culturais que permearam a realização do PRODECER, e à necessidade de estudos sobre dinâmicas sociais e culturais nas regiões de Cerrado (SANTOS, 2016), busquei lançar luzes sobre um dos aspectos fundamentais do Programa capaz de indicar novas possibilidades em termos de pensamento e ação sobre desenvolvimento: as experiências de pessoas que se deslocaram para regiões de Cerrado no contexto do Programa, oriundas de outros estados e regiões do País, especificamente os de origem japonesa que migraram para o município de Paracatu, por caminhos metodológicos indicados pela história oral.

O objetivo geral da pesquisa foi obter expressões e sentidos sobre processos de desenvolvimento a partir da trajetória de pessoas, famílias e grupos que compõem a comunidade nikkei de Paracatu, que migraram para o Município na segunda metade do Século XX, no contexto da abertura de novas fronteiras agrícolas em regiões de Cerrado, proporcionada por programas como o PRODECER. Os objetivos específicos desta pesquisa incluíram conhecer, interpretar e registrar experiências da referida comunidade nikkei; compreender dinâmicas que caracterizaram a realização do PRODECER em Paracatu no que se refere à participação de colonos agrícolas de origem japonesa; e identificar fatores nas dimensões pessoal, familiar e comunitária capazes de revelar outros sentidos, expressões e perspectivas sobre o desenvolvimento.

$\mathrm{Na}$ obtenção de outros possíveis sentidos, expressões, leituras e perspectivas sobre processos de desenvolvimento a partir da trajetória da comunidade nikkei de Paracatu, considerei teorias de desenvolvimento existentes e abordagens dos estudos culturais e pós-coloniais que complexificam o pensamento sobre desenvolvimento, e propus um entendimento sobre processos de desenvolvimento como experiências que emergem de subjetividades em sua diversidade e complexidade.

Busquei atingir os propósitos da tese que embasou este artigo pela obtenção de relatos orais, por meio de conversas, baseadas em um roteiro de questões, com 23 pessoas de 11 famílias de origem japonesa residentes em Paracatu, as quais continham membros que participaram do PRODECER ou acompanharam sua realização sem participar diretamente. As questões contidas no roteiro referiram-se aos motivos que levaram os entrevistados e/ou seus parentes e agregados a participarem do PRODECER, a como era a vida dessas pessoas antes de sua participação no PRODECER, a como tomaram conhecimento sobre o Programa, a que conhecimento tinham do Programa, a como se vivia durante a realização do PRODECER, como eram as relações dentro das cooperativas às quais estavam associados e com pessoas de fora delas, quais foram as experiências obtidas a partir dessa participação, a possíveis mudanças realizadas e novas perspectivas surgidas, entre outras.

Enquanto metodologia que permite a constituição de fontes históricas e documentais pelo registro de testemunhos, a oralidade oferece a possibilidade de se reinterpretar e compreender objetos de estudo de maneira mais ampla e aprofundada. 
A história oral possibilita estudar acontecimentos históricos, instituições, grupos sociais, movimentos, etc. à luz de depoimentos de pessoas que deles participaram ou os testemunharam, especialmente recuperar acontecimentos pouco esclarecidos ou nunca evocados, experiências e impressões pessoais, que não se encontram em documentos de outra natureza (VANSINA, 1966; ALBERTI, 2007). Além de servir como importantes fontes de conhecimento sobre o passado, narrativas orais têm a capacidade de reabrir portas do passado e de questioná-lo, bem como de alargar o campo de trabalho do pesquisador e questionar a superioridade de assertivas situadas em documentos escritos, geralmente relacionados a contextos e grupos sociais dominantes (NUNES, 2009; MAGALHÃES, 2013). Desse modo, a oralidade amplia a possibilidade de se obter perspectivas não hegemônicas e mais próximas às dinâmicas e urgências da realidade.

Para discorrer sobre as duas linhas gerais em que foram realizados estudos sobre o PRODECER, a história oficial sobre o PRODECER foi obtida mediante coleta e análise de documentos governamentais relativos a acordos entre Brasil e Japão e protocolos complementares sobre cooperação técnica, e a políticas de cooperação técnica internacional dos dois países. Também foram pesquisados relatórios e informativos oficiais sobre o Programa e material relacionado, elaborado por instituições de ambos os países, e notícias sobre iniciativas e resultados do Programa. Por sua vez, estudos que criticam o PRODECER foram buscados desde a tese pioneira da geógrafa Pessôa (1988) até o mencionado artigo de Santos (2016), passando pelos sociólogos Pires (1996, 2000) e Osada (1999), pelos geógrafos Mendonça (2004), Santos (2007) e Pessôa e Inocêncio (2014).

Além da busca de outro caminho para se compreender processos de desenvolvimento ante a polarização verificada nos estudos sobre o PRODECER, proposto pela via da oralidade, a realização deste trabalho se justificou pelo interesse manifestado por representantes da comunidade de origem japonesa de Paracatu em registrar suas trajetórias entre as histórias de comunidades nikkeis em contextos regionais e locais do Brasil. Em artigo sobre a presença nipônica em Paracatu, fruto de pesquisa demandada no contexto das comemorações do centenário da imigração japonesa por um grupo de agricultores que participaram do PRODECER no Município, as historiadoras Pimentel e Botelho (2007, p. 2) relatam que, no decorrer de entrevistas realizadas com tais produtores rurais, foi discutida a relação entre a história desse empreendimento e a trajetória de vida dessas pessoas, já que "a reunião deles naquela cidade e o associativismo resultante decorreram de sua participação no projeto". Percebeu-se que não havia consenso sobre o sentido a ser conferido à comemoração do centenário e, no que se refere à questão dos prováveis patrocinadores de um livro sobre a colônia, houve um questionamento "a respeito de quem teria interesse em financiar a história de um empreendimento "que não tinha dado certo" (PIMENTEL; BOTELHO, 2007, p. 2).

Com vistas a entender processos de desenvolvimento a partir de perspectivas e experiências de pessoas e grupos humanos que não tiveram direito à história, e 
em seguimento à defesa realizada por Bhabha (1998) de se considerar histórias de migrantes e outros grupos humanos em condições de deslocamento geográfico, político, econômico, social e cultural como terreno da literatura mundial, em lugar da transmissão universalista de culturas nacionais, as trajetórias, experiências, memórias, impressões e sentimentos dos nikkeis considerados nesse estudo são capazes de enriquecer em detalhes e experiências, indicar contrapontos, e trazer novas perspectivas sobre processos de desenvolvimento diversos em níveis local, regional, nacional e mundial, incluindo a imigração japonesa ao Brasil, as relações de cooperação econômica e técnica entre Brasil e Japão, a realização do PRODECER, e a própria trajetória da comunidade nikkei de Paracatu.

Além da possibilidade de enriquecer campos de estudo que lidem com as temáticas da cooperação, do desenvolvimento e correlatas, a pesquisa poderá inspirar o pensamento e a realização de ações nessas áreas que considerem, da concepção à avaliação, para além dos interesses geopolíticos e necessidades econômicas dos países envolvidos, saberes, experiências, opiniões e aspectos culturais de todas as pessoas e grupos populacionais envolvidos, reconhecendo-os como sujeitos.

\section{Análise e comentário do conteúdo}

Com base em ligeira sumarização do referencial teórico existente sobre desenvolvimento, aplicado a comunidades humanas, pode-se entendê-lo, de maneira geral, como um processo histórico complexo, multidimensional, relacionado a diversos fatores, como, por exemplo, crescimento econômico, distribuição de renda, abertura política, expectativa de vida, acesso a sistemas de educação e saúde, indicadores de ciência, tecnologia e inovação, e preservação ambiental. Na intenção de obter perspectivas outras de desenvolvimento a partir da comunidade nikkei de Paracatu, pretendi ir além desses fatores, sem, contudo, desconsiderar a relevância deles para o entendimento sobre processos de desenvolvimento desde o surgimento e a consolidação de teorias e abordagens de desenvolvimento.

No Dicionário Crítico das Ciências Sociais dos Países de Fala Oficial Portuguesa, Furtado (2014, p. 91) considera que “o termo 'desenvolvimento' é, seguramente, um dos mais ambíguos nas ciências sociais, ainda que se possa dizer que existe um relativo consenso quanto ao seu significado bem como à possibilidade de sua replicabilidade". No que se refere ao relativo consenso, o autor esclarece que o desenvolvimento é assumido como constituindo um valor, um desejo universal, um objetivo a atingir por indivíduos, países e entidades supranacionais há décadas, se não séculos. Furtado (2014) chama atenção para o predomínio de uma visão eurocêntrica em acepções de desenvolvimento, construídas tendo como referência ideológica e empírica as sociedades da Europa Ocidental e da América do Norte, que constituiriam modelos de desenvolvimento, significando progresso econômico e social. Por outro lado, as demais sociedades corporificariam o reverso, na forma do subdesenvolvimento, ou estariam 
em vias de desenvolvimento, estágios caracterizados por pobreza, ausência ou baixa produção econômica, e acesso restrito a bens sociais básicos como saúde, educação, alimentação e habitação. No mesmo raciocínio centrado em dicotomias, utilizadas para definir e diferenciar países, vale comentar os termos modernidade versus tradição, que podem ser considerados análogos a desenvolvimento versus subdesenvolvimento, progresso versus atraso, e similares.

As teorias do desenvolvimento foram consolidadas como tais após a Segunda Guerra Mundial, e enfocando questões econômicas, quando países industrializados buscaram promover a reconstrução das nações devastadas pelo conflito, o crescimento do comércio internacional e a transformação econômica dos países subdesenvolvidos. Nesse contexto de reestruturação da estrutura de poder mundial e de reconfiguração das relações políticas e econômicas mundiais, marcado pelo declínio dos países imperialistas, pela ascensão e consolidação da hegemonia dos Estados Unidos, e por movimentos independentistas e consequente emergência de novos países na África e na Ásia, a América Latina buscava superar a condição de subdesenvolvimento com políticas e programas voltados ao progresso industrial. As teorias de desenvolvimento do período, que equalizavam desenvolvimento e crescimento econômico, compreendiam e faziam entender o desenvolvimento como um estágio avançado, caracterizado por altos níveis de industrialização e urbanização, observados em nações como os Estados Unidos e países da Europa ocidental, que poderia ser alcançado por países subdesenvolvidos caso seguissem uma trajetória linear composta de etapas sucessivas de modernização (DOS SANTOS, 1994; ESCOBAR, 2014).

Apesar das inúmeras críticas à visão de desenvolvimento que sugere aos países subdesenvolvidos seguir uma trajetória de progresso única, cumprida pelos industrializados (ROSTOW, 1960), ainda se faz presente em discussões sobre desenvolvimento e prevalece orientando políticas e projetos de desenvolvimento nos dias atuais. O PRODECER, que tinha entre seus objetivos a modernização da agricultura em regiões de Cerrado, representa um exemplo nesse sentido, repercutindo, nos dias atuais, em planos e atividades voltados à expansão da produção e exportação agropecuária e ao desenvolvimento econômico e social na região brasileira denominada como Matopiba, considerada a última fronteira agrícola brasileira, compreendendo o bioma Cerrado dos estados do Maranhão, Tocantins, Piauí e Bahia (SANTOS, 2016; EMBRAPA, 2017).

Na medida em que dialoga com discussões sobre concepções de desenvolvimento, considero pertinente fazer referência ao pensamento de Benjamin (1987, p. 115) sobre progresso e modernidade, identificados em um "monstruoso desenvolvimento da técnica, sobrepondo-se ao homem", ligados à evolução do modelo econômico e civilizatório do capitalismo. Crítico da ideologia do progresso como discurso hegemônico que o concebe como fenômeno linear, ilimitado e automático, Benjamin (1987, p. 229) considera o progresso um "conceito dogmático [...] sem qualquer vínculo com a realidade", e defende o aniquilamento da ideia de progresso como contínuo da história, ou seja, a ruptura com a continuidade da marcha do progresso, 
em um tempo vazio e homogêneo, como sendo a própria história da humanidade. Nessa ruptura, propõe "escovar a história a contrapelo", ou seja, a partir de narrativas dos vencidos e não em empatia com rotas históricas unidirecionais escritas pelos vencedores, permitindo lançar luzes ao que se perdeu ou ao que foi emudecido ao longo da marcha do progresso (BENJAMIN, 1987, p. 225).

Nesta pesquisa, a oralidade, valorizada nas considerações benjaminianas sobre a transmissão de experiências, permitiu recuperar acontecimentos e experiências não revelados ou pouco esclarecidos, apenas conhecidos a partir das memórias dos entrevistados, que podem ser consideradas, em geral, subterrâneas, marginalizadas e silenciadas em relação à história oficial sobre o PRODECER. O pensamento póscolonial ${ }^{4}$ de Bhabha $(1998$, p. 34) sobre a questão da agência subalterna indica a necessidade de se analisar e entender a modernidade a partir das perspectivas dos que são relegados à margem, tidos como minoritários, excluídos e/ou diaspóricos, e de assumir a responsabilidade pelos passados não ditos e não representados, "que assombram o presente histórico". Ao constatar que "o presente não pode mais ser encarado simplesmente como uma ruptura ou um vínculo com o passado e futuro", como o fazem concepções do tempo como linear, sequencial e sincrônico, Bhabha (1988, p. 23) dialoga com Benjamin (1987) sobre o estabelecimento de uma concepção do presente como o tempo do agora, por uma ruptura com o curso homogêneo - o contínuo - da história.

Em Bhabha (1998), verifica-se que o pós-colonial apresenta um comprometimento com a crítica ao colonialismo e a desconstrução de seu discurso, o que pode ser realizado a partir de perspectivas de minorias. No que se refere ao colonialismo em discursos de modernidade e desenvolvimento, Bhabha (1998, p. 334), indica "um parentesco entre os paradigmas normativos da antropologia colonial e o discurso contemporâneo das agendas de auxílio e desenvolvimento", atentando para o perigo de que discursos ocultem a fato de que "as estruturas hegemônicas do poder sejam mantidas em uma posição de autoridade através de uma mudança de vocabulário na posição de autoridade".

Em discussão sobre a relação entre o fenômeno pós-colonial e o ressurgimento da questão multicultural, Hall (2003, p. 56) afirma que o pós-colonial "não sinaliza uma simples sucessão cronológica do tipo antes/depois", não implica "que os problemas do colonialismo foram resolvidos ou sucedidos por uma época livre de conflitos", pois persistem problemas de dependência, subdesenvolvimento e marginalização, em nova configuração (HALL, 2003).

A teorização realizada a partir da trajetória da comunidade nikkei de Paracatu é representada pela obtenção de entendimentos sobre processos de desenvolvimento

4 Abordagens dos estudos pós-coloniais, ou do pós-colonialismo, apresentadas por autores como Bhabha (1998), Said (1996) e Hall (2003), dedicam-se à análise de tensões entre centro e periferia, revelam a permanência de assimetrias nas relações entre antigas colônias e metrópoles, e estimulam a busca por alternativas ao eurocentrismo. Conceitos-chave do pós-colonialismo incluem diáspora, hibridismo e diferença cultural. 
como experiências que emergem de subjetividades em sua diversidade e complexidade. Essas experiências de desenvolvimento surgidas de subjetividades diversas e complexas guardam características semelhantes e elementos comuns que as permitem ser agrupadas em dimensões ou categorias descritivas que se revelaram predominantes ao longo das trajetórias de vida, nomeadamente migração, trabalho, educação, comunidade e cultura. A análise estrutura-se considerando as cinco dimensões em interação com conceitos e abordagens chave dos estudos culturais e pós-coloniais, incluindo diáspora, entre-lugar, hibridismo, orientalismo, raça e minorias, que foram identificados ao longo da trajetória da comunidade estudada.

Sequencialmente, como geralmente ocorre em muitas obras sobre a presença japonesa no Brasil (HANDA, 1987; NOGUEIRA, 1973; SAITO, 1980; ARAI; HIRASAKI, 2008; HARADA, 2013), as trajetórias de vida dos nikkeis residentes em Paracatu podem ser divididas em quatro momentos considerados comuns aos entrevistados, com ligeiras diferenças cronológicas: 1) migração do Japão para o Brasil, no contexto do ciclo cafeeiro no Brasil e da modernização japonesa - Era Meiji; 2) formação de comunidades nikkeis em diversas cidades brasileiras e repercussões da Segunda Guerra Mundial e do nacional-desenvolvimentismo do governo Vargas; 3) mudança para Paracatu no contexto de planos, programas e projetos de modernização agrícola no Cerrado, como o PRODECER; 4) deslocamento ao Japão como parte do movimento decasségui e retorno ao Brasil.

Em um primeiro momento, analiso a dimensão da migração pelas experiências de deslocamento dos nikkeis entrevistados desde a vinda de seus familiares para o Brasil. As dimensões do trabalho e da educação ganham destaque como aspirações, valores e ações ao longo de trajetórias de vidas entre lugares - remetendo tanto a localidades geográficas quanto a referências socioculturais -, que se revelam marcadas por diversos hibridismos. Comunidade e cultura, por sua vez, são dimensões que incluem a formação de comunidades nikkeis pelo Brasil, a constituição de associações como a Associação Cultural Esportiva Recreativa Nipo-Brasileira de Paracatu (ACENP) e a Casa do Estudante Nipo-Brasileiro em Brasília, e as práticas culturais de origem japonesa ou não realizadas nesses e outros espaços.

As histórias de vida dos nikkeis e de suas famílias são marcadas por várias diásporas, na forma de deslocamentos populacionais não apenas geográficos, de um território para outro, mas igualmente caracterizados por significativas mudanças nas condições econômico-sociais e identidades culturais dessas pessoas e famílias. De modo geral, na busca por melhores condições de vida, os nikkeis e suas famílias realizaram movimentações entre espaços geográficos, aproveitaram oportunidades de trabalho no campo e experimentaram deslocamentos socioculturais por choques e discriminações.

O deslocamento de japoneses ao Brasil realizou-se, também, à revelia de aspectos de processos de desenvolvimento ou modernização que comprometeriam aspirações de desenvolvimento individuais e coletivas. Exemplos desses aspectos são representados pela preferência do Brasil por imigrantes europeus, cuja vinda era associada a uma nova 
fase política fundada em ideais positivistas de ordem e progresso social (DEZEM, 2005), e por ideias de cunho orientalista ${ }^{5}$, fundadas na ameaça racial e no perigo imperialista que japoneses representariam ao Brasil, utilizadas por representantes do Governo brasileiro, incluindo membros do corpo diplomático, para justificar posicionamentos contrários à imigração japonesa. A aparentemente simples convergência de interesses entre Brasil e Japão na imigração de japoneses ao Brasil, reduzindo-se o excedente populacional de um lado e abastecendo mão-de-obra nos cafezais de outro, enfrentou posicionamentos desfavoráveis expressos em legislações e documentos oficiais, e representados em textos literários, artigos de revistas e charges, que também revelavam as imagens que pessoas comuns faziam dos imigrantes japoneses (LEÃO NETO, 1990; TAKEUCHI, 2008; 2009; HASHIMOTO, 2012).

Como os depoentes, entendi que o Brasil representava uma oportunidade para muitos japoneses, que lidassem ou não com agricultura. Além da diversidade de origens, atividades e experiências no Japão, diversas foram as condições em que embarcaram para o Brasil. Também compreendi que as motivações dos imigrantes, geralmente associadas a "ganhar muito dinheiro e ir embora para o Japão", como mencionou a Sra. H. E., não se reduziram à busca por melhorias financeiras no curto prazo que os permitam retornar ao local de origem, sobretudo nas reticências em falas do Sr. W. E.: "vieram para procurar um novo horizonte, alguma coisa para..."; "Então... alguns [não todos] vieram por isso [ganhar dinheiro e retornar ao Japão]" ${ }^{6}$. Os depoentes indicaram, ainda, falta de planejamento e organização do movimento migratório e da alocação dos japoneses nas fazendas de café. Considerando que, "na verdade, era uma substituição de trabalhadores escravos, mas não foi exatamente como trabalho escravo", referiramse a dificuldades de adaptação dos japoneses no que se refere a moradia, alimentação, e a frustrações na intenção de imigração temporária, em razão de dívidas com os fazendeiros, ao invés da imaginada sobra de dinheiro que seria obtida com o sucesso na colheita, conforme sugeriam as propagandas no Japão.

Pausada entre os anos de 1942 a 1952, do rompimento ao restabelecimento das relações diplomáticas entre Brasil e Japão, a diáspora continuou no período pósguerra, inclusive devido às consequências negativas do conflito para a população japonesa. Apesar de o restabelecimento das relações diplomáticas ter permitido o avanço do programa de imigração de agricultores japoneses conhecido como Cotia

5 O orientalismo é definido por Said (1996) em três sentidos interdependentes: acadêmico, imaginativo e institucional, remetendo tanto a ensino e pesquisa sobre o Oriente, quanto a um estilo de pensamento baseado numa distinção ontológica e epistemológica entre Oriente e Ocidente, e ainda a um estilo ocidental para lidar com o Oriente, ou seja, descrever, produzir, reestruturar e dominar o Oriente. Trata-se de um empreendimento cultural que ganhou força e identidade no contraste com o Oriente, visto como subterrâneo e inferior e cuja representação colaborou para a legitimação dos interesses colonialistas ocidentais.

6 Entrevista realizada em 27 de janeiro de 2017 com o Sr. W. E., nissei, natural de Presidente BernardesSP, e a Sra. H. E., nissei, natural de Itapeva-SP. O casal vive em Paracatu desde 1981. 
Seinen, a comunidade japonesa residente no Brasil ainda se ressentia dos impactos da Segunda Guerra Mundial, envolvendo conflitos internos, violência física e simbólica, e instabilidade entre os próprios japoneses e descendentes, decorrentes de políticas repressivas aos imigrantes de países do Eixo durante o governo Vargas.

Ao contar sobre suas origens, o Sr. Tunemaça Shimada comenta sobre os efeitos do conflito sobre as comunidades japonesa, alemã e italiana no Brasil, inclusive na forma de repressão sobre sua família: o pai do depoente foi levado à prisão por falar no idioma japonês em tempos de guerra, o que era proibido quando Brasil e Japão estavam em lados opostos.

\begin{abstract}
Em Assaí, e em vários lugares do Brasil, o japonês, o alemão e o italiano não eram bem quistos, porque os três países eram aliados. Não acontecia de bater à toa, não assim, mas... um dia, meu pai voltou para Assaí, encontrou alguém lá, e falou konnichi wa, dou desu ka, genki desu ka... e a polícia levou ele para o xadrez, só porque falou em japonês. Foi preso. Estava em guerra, né? Mas isso foi por uma noite só, como um castigo. Desde que a guerra acabou e tudo ficou em paz, logo o Governo brasileiro... parou de perseguir. (Tunemaça Shimada, 80 anos, nissei, natural de Matão-SP, vive em Paracatu desde 1986) ${ }^{7}$
\end{abstract}

No tocante à aludida instabilidade entre nikkeis, a comunidade japonesa residente no Brasil dividiu-se entre pessoas que não admitiam a derrota na Segunda Guerra, chamados vitoristas, e pessoas que acreditaram que o Japão havia sido derrotado no conflito, os derrotistas, como vivenciaram as famílias dos Srs. Guentaro Alimura e Mituo Muraoka ${ }^{8}$, de opinião vitorista. Certos da vitória japonesa em quaisquer conflitos - por terem aprendido que "japonês nunca perde" - e mantendo esperança de retorno à terra natal, os pais dos depoentes os retiraram das escolas onde aprendiam português, conhecimento que seria obsoleto no Japão. O genitor do Sr. Alimura teve a oportunidade de conhecer, "com olho", em 1953, o Japão do pós-guerra, quando "ainda tinha muito lugar que foi bombardeado". Apenas dessa forma acreditou nas notícias segundo as quais o Japão havia sido derrotado no conflito, optando por viver no Brasil. Nessa época, os Srs. Alimura e Muraoka contavam, respectivamente, 18 e 14 anos, idades consideradas avançadas pelos próprios depoentes para aprender português.

Finalizada a Segunda Guerra Mundial, que havia causado divisões entre brasileiros e japoneses e conflitos no interior de comunidades nikkeis, passa-se a um período de maior integração de japoneses e descendentes à sociedade brasileira. Essa fase é caracterizada pela presença crescente de nikkeis na indústria, no comércio, na política,

7 Entrevista realizada em 23 de janeiro de 2017.

8 As falas foram proferidas em uma mesma entrevista com ambos os depoentes, ambos nisseis, realizada em 18 de janeiro de 2017. O Sr. Guentaro Alimura tem 81 anos, é natural de Vera Cruz-SP e vive em Paracatu desde 1983. O Sr. Mituo Muraoka tem 77 anos, nasceu em Uraí-PR e vive em Paracatu desde 1981. 
na administração pública, na vida acadêmica e nas atividades culturais e artísticas - além da agricultura (MOTOYAMA; OKUBARO, 2016), como é o caso da participação, no PRODECER, de descendentes de japoneses associados a uma cooperativa constituída por imigrantes japoneses.

Filhos da diáspora japonesa do início do Século XX, pessoas como os Srs. Alimura, Muraoka e W.E., protagonizaram um novo deslocamento em busca de oportunidades para melhorar suas condições de vida, e de suas famílias, por meio da participação em projetos de colonização do PRODECER em Paracatu - Novo Mundo e Entre Ribeiros I - como cooperados da CAC e da Coopervap. O trabalho como colonos agrícolas no PRODECER representava um caminho de desenvolvimento seguido pelos nikkeis em contextos de mudanças tecnológicas e trabalhistas: a mecanização, que substituiu o trabalho braçal, exigia áreas maiores para locomoção; e a aplicação de direitos trabalhistas em áreas rurais onerava os produtores que empregavam muita mão-de-obra.

O casal W. E. e H. E., participante do projeto Mundo Novo, esclarece tanto "a ideia dos governos brasileiro e japonês" quanto "o objetivo do nosso grupo", ou seja, os motivos da mudança de agricultores cooperados vindos da região Sul do Brasil, filhos de imigrantes estrangeiros, para regiões de Cerrado. Esses agricultores tinham interesse em "conseguir uma área maior para produção agrícola, terras mais baratas" comparativamente às de localidades em que viviam, nos estados de São Paulo e Paraná. O Brasil tinha interesse em "construir um polo de desenvolvimento agrícola em Paracatu", onde, "em termos de economia, não havia quase nada [...], apenas gado e um pouco de mineração". O Japão procurava "outros lugares onde pudessem ter uma fonte, uma segunda alternativa de compra de produtos", haja vista o embargo norteamericano às exportações de soja. Desse modo, "essa cooperação nipo-brasileira não se deu pensando na colônia japonesa" presente no Brasil, em que pese a participação de nikkeis e de uma cooperativa estabelecida por imigrantes japoneses no Programa.

$\mathrm{Na}$ busca por suas aspirações de desenvolvimento, em muitos casos pela participação no PRODECER, muitas foram as pedras no caminho e intensas as frustrações de expectativas. As adversidades relatadas pelos nikkeis podem ser agrupadas em três categorias: 1) condições de clima, umidade e altitude; 2) impactos de políticas econômicas sobre o financiamento agrícola; 3 ) choques culturais no contato com a sociedade paracatuense. Em todas essas categorias, as impressões dos nikkeis sobre as adversidades podem ser resumidas nas falas do Sr. Shimada: "não era tão... como a gente calculava, né!?"

As trajetórias de lutas dos nikkeis que passaram a viver em Paracatu, analogamente às de seus antecessores, incluem, para além da experiência na agricultura, as dimensões da educação, especialmente a formação dos filhos, e da cultura, na forma da preservação de tradições de origem japonesa. A constituição da Associação Cultural Esportiva Recreativa Nipo-Brasileira de Paracatu - ACENP, conhecida como Kaikan, e a construção da Casa do Estudante Nipo-Brasileiro em Brasília, representam importantes marcos da presença nikkei em Paracatu e região. 
Nas palavras do Sr. Shimada, "a amizade foi rápida entre desconhecidos"; ainda que desconhecidos, tinham em comum a ascendência japonesa e vieram de estados e cidades próximas. Complementando com o que comentou o Sr. Muraoka, constata-se que "japoneses, quando juntam em três pessoas, ainda que desconhecidos, já formam associação", com a ressalva de que essa associação entre nikkeis vindos de fora de Paracatu ocorreu concomitantemente ao contato dos nikkeis com a sociedade local.

Mais do que associações destinadas à preservação de tradições culturais, entendo como ambientes de crescentes hibridismos a ACENP/Kaikan e a ACENBB/Casa do Estudante Nipo-Brasileiro. De um lado, tratam-se de locais imaginados e construídos, em resposta a mudanças, na forma do deslocamento de famílias nikkeis a Paracatu e da elevação do nível de escolaridade dos descendentes de nikkeis que haviam se deslocado para a localidade. De outro, são lugares também frequentados por pessoas não descendentes de japoneses, que estudam língua japonesa, praticam esportes originários do Japão e/ou comuns naquele país, e participam de festividades culturais diversas. Desse modo, após um tempo de seu estabelecimento, as atividades de ambas as instituições acabaram por transbordar para fora das comunidades nikkeis de modo a beneficiar também pessoas não descendentes.

Conceito caro ao pós-colonialismo, hibridismo remete a mistura, mestiçagem, combinação de dois ou mais elementos heterogêneos. Assemelha-se à crioulização, definida por Glissant (2001, p. 8) como um fenômeno pelo qual "as culturas do mundo colocadas em contato umas com as outras de maneira fulminante e absolutamente consciente transformam-se". Hall (2003, p. 31) explica que, realizada a diáspora, o "resultado híbrido não pode mais ser facilmente desagregado em seus elementos 'autênticos' de origem".

Em Paracatu, as transformações pelas quais passaram as culturas que se colocaram em co-presença geraram resultados híbridos diversos, que dificilmente poderiam retornar aos elementos originários, apesar dos esforços em se manter tradições de origem japonesas. Os nikkeis entrevistados têm suas trajetórias marcadas pela experiência da fronteira entre culturas em movimento. Os processos de desenvolvimento dessas pessoas ocorrem nos espaços intersticiais complexos e dinâmicos gerados pela diáspora, chamados entre lugares, em que são negociados valores culturais, interesses comunitários e experiências intersubjetivas e coletivas de nação (BHABHA, 1998). Os hibridismos permanecem como dinâmicas infindáveis, à medida em que ocorrem mudanças culturais tanto na comunidade nikkei como na sociedade paracatuense. Pontes e redes são construídas entre os lugares, conectando referências culturais tidas como distintas, e gerando novas e complexas realidades.

Os processos de desenvolvimento dos nikkeis se revelaram como experiências vividas em dimensões como migração, trabalho, educação, comunidade e cultura em interações diversas e complexas -, no sentido de se alcançar aspirações pessoais e coletivas diversas de desenvolvimento. Trabalho não restrito a ocupação, ofício ou emprego, mas significando principalmente esforço, dedicação, empenho. Educação 
não apenas no sentido de formação realizada em instituições de ensino e de pesquisa, mas também remetendo à transmissão de saberes, tradições, comportamentos e outros aspectos, nas experiências do dia-a-dia e na vivência familiar e comunitária. Comunidade como grupo humano que mantém traços culturais diferenciados em relação a pessoas e grupos de outras origens étnicas, mas representa um dos segmentos da megadiversa sociedade brasileira. Cultura como conjuntos de saberes e práticas em contínua reelaboração.

Para realizar suas aspirações, os nikkeis assumiram a iniciativa pelo próprio desenvolvimento, ora aproveitando oportunidades abertas por processos como a imigração japonesa ao Brasil, o PRODECER e o movimento decasségui ao Japão, construindo, participando e oportunizando meios de desenvolvimento. Nas localidades em que os nikkeis entrevistados e suas famílias residiram, especialmente em Paracatu, foram sujeitos de seu próprio desenvolvimento ao instalar sistemas de irrigação para superar condições climáticas adversas à produção agrícola, ao qualificar-se e garantir ensino formal e educação informal aos descendentes, ao construir associações dedicadas à preservação de tradições culturais japonesas e ao elaborar estratégias de integração com a população local.

\section{Considerações finais}

No contexto das comemorações dos 110 anos do início da imigração japonesa, e decorridos poucos anos das celebrações dos 120 anos do estabelecimento de relações diplomáticas, ou seja, quando muito se enaltece, no Brasil e o Japão, o sucesso da integração de japoneses e descendentes à sociedade brasileira, esta pesquisa me permitiu entender esse processo em complexidades que só me poderiam ser reveladas por quem as viu e viveu.

Apesar de muito já ter sido produzido sobre a presença japonesa no Brasil, ainda há muito que se conhecer sobre a experiência de comunidades nikkeis em várias localidades do vasto território brasileiro, a exemplo da que reside no município de Paracatu. Sabe-se da modernização agrícola e da produtividade das regiões de Cerrado, mas pouco se conhece sobre a experiência de quem esteve na lida diária com a terra, e de quem acompanhou esse trabalho dedicando-se a outras atividades, em todos os casos em uma localidade da qual tinham pouco ou nenhum conhecimento. Aqui, parece se repetir a trajetória dos primeiros imigrantes que vieram ao Brasil, genitores dos futuros agricultores que buscariam novas fronteiras no Cerrado.

Fontes escritas, orais e imagéticas, em complementaridade, proporcionaram visibilidade a experiências de desenvolvimento de pessoas e grupos que conformam a comunidade nikkei de Paracatu, em sua diversidade e complexidade. Relatos orais expressos pelos depoentes, em articulação com suas memórias, permitiram-me conhecer a dimensão do vivido e também do revivido relativamente a processos de desenvolvimento cuja história se imagina plenamente investigada, como a realização de um programa binacional voltado ao desenvolvimento dos Cerrados pela modernização agrícola. 


\section{Referências Bibliográficas}

ALBERTI, Verena. Manual de História Oral. $3^{\mathrm{a}}$ ed. Rio de Janeiro: Editora FGV, 2007.

ARAI, Jhony; HIRASAKI, Cesar. 100 anos da imigração japonesa no Brasil. Trad. Kenji Miyo e Kazunari Akaki. São Paulo: Imprensa Oficial do Estado de São Paulo; Bunkyo Sociedade Brasileira de Cultura Japonesa e de Assistência Oficial, 2008.

BENJAMIN, Walter. Magia e técnica, arte e política. Ensaios sobre literatura e história da cultura. Obras escolhidas. Trad. Sergio Paulo Rouanet. V. 1, $3^{\text {a }}$ ed. São Paulo: Brasiliense, 1987.

BHABHA, Homi. O local da cultura. Trad. Miriam Ávila, Eliana Lourenço de Lima Reis, Gláucia Renate Gonçalves. Belo Horizonte: Editora UFMG, 1998.

BRASIL. Ministério da Agricultura, Pecuária e Abastecimento/Agência de Cooperação Internacional do Japão. Programa de Cooperação Nipo-Brasileira para o Desenvolvimento Agrícola dos Cerrados. Estudo de Avaliação Conjunta - Relatório Geral, No 48. Brasília, janeiro de 2002.

DEZEM, Rogério. Matizes do "amarelo": A gênese dos discursos sobre os orientais no Brasil (1878-1908). São Paulo: Associação Editorial Humanitas, 2005.

DOS SANTOS, Theotonio. A revolução científico-tecnológica, a nova divisão internacional do trabalho e o sistema econômico mundial. Cadernos ANGE, Vitória/ES, 1994.

ESCOBAR, Arturo. Territories of difference: Place, movements, life, redes. Durham, Duke University Press, 2008.

Empresa Brasileira de Pesquisa Agropecuária. Matopiba: Sobre o tema. Disponível em: $<$ https:// www.embrapa.br/tema-matopiba>. Acesso em 10 de dezembro de 2017.

FURTADO, Cláudio Alves. Desenvolvimento. FURTADO, Cláudio Alves; SANSONE, Livio (Orgs.). Dicionário Crítico das Ciências Sociais dos Países de Fala Oficial Portuguesa. Salvador: EDUFBA, 2014, p. 91-103.

GLISSANT, Édouard. Introdução a uma poética da diversidade. Trad. Elnice Albergaria Rocha. Juiz de Fora: Editora UFJF, 2001.

HALL, Stuart. Da diáspora: Identidades e mediações culturais. Org. Liv Sovik. Trad. Adelaine La Guardia Resende, Ana Carolina Escosteguy, Claudia Alvares, Francisco Rudiger Sayonara Amaral. Belo Horizonte: Editora UFMG; Brasília: Representação da UNESCO no Brasil, 2003.

HANDA, Tomoo. O imigrante japonês: História de sua vida no Brasil. São Paulo: T.A. Queiroz/ Centro de Estudos Nipo-Brasileiros, 1987.

HARADA, Kiyoshi (Coord.). O nikkei no Brasil. $3^{\mathrm{a}}$ ed. São Paulo: Cadaris Comunicação, Associação para Comemoração do Centenário da Imigração Japonesa para o Brasil, 2013.

HASHIMOTO, Shirlei Lica Ichisato. As representações dos japoneses nos textos modernistas brasileiros: Mário de Andrade, Oswald de Andrade e Juó Bananére. Tese (Doutorado) Universidade de São Paulo, Programa de Pós-Graduação em Literatura Brasileira, 2012. 
LEÃO NETO, Valdemar Carneiro. A Crise da Imigração Japonesa no Brasil (1930-1934): contornos diplomáticos. Brasília: Fundação Alexandre de Gusmão, 1990.

MAGALHÃES, Nancy Alessio. Fios de testemunhos de lutas: memória, imagem e história oral. In: Marcas da terra, marcas na Terra. Um estudo da terra como patrimônio cultural e histórico. Guarantã do Norte (1984-1990). Brasília: Editora UnB, 2013.

MENDONÇA, Marcelo Rodrigues. A urdidura espacial do capital e do trabalho no cerrado do sudeste goiano. Tese de Doutorado - Programa de Pós-Graduação em Geografia, UNESP, 2004.

MOTOYAMA, Shozo; OKUBARO, Jorge. Do Conflito à Integração - Uma História da Imigração Japonesa no Brasil (1941-2008). Volume II. São Paulo: Editora Paulo’s, 2016.

NOGUEIRA, Arlinda Rocha. A Imigração para a Lavoura Cafeeira Paulista (1908/1922).

São Paulo: Instituto de Estudos Brasileiros, 1973.

NUNES, José Walter. Narrativa histórica no filme documentário: Realidade e ficção se encontram? In: DUARTE, Geni Rosa; FROTSCHER, Méri; LAVERDI, Robson. Práticas socioculturais como fazer histórico: Abordagens e desafios teórico-metodológicos. Cascavel, PR: Edunioeste, 2009, pp. 139-160.

OLIVEIRA MELLO, Antônio de. As minas reveladas: Paracatu no tempo. Paracatu: Edição da Prefeitura Municipal de Paracatu, 1994.

. Paracatu meu bem querer. $3^{a}$ ed. Paracatu: Edição da Prefeitura Municipal de Paracatu, 2007.

OSADA, Neide Mayumi. PRODECER: Projetos no cerrado e dívidas agrícolas. Carta Asiática, São Paulo, 15 de maio de 1999.

PESSÔA, Vera Lúcia Salazar. Ação do Estado e as transformações agrárias nos Cerrados das zonas de Paracatu e Alto Paranaíba/MG. Tese de Doutorado - ICGE-UNESP. Rio Claro, SP, 1988.

PESSÔA, Vera Lúcia Salazar; INOCÊNCIO, Maria Erlan. O PRODECER (Re)visitado: As engrenagens da territorialização do capital no Cerrado. CAMPO-TERRITÓRIO: Revista de geografia agrária, Edição especial do XXI ENGA-2012, pp. 1-22, Jun. 2014.

PIRES, Mauro Oliveira. Desenvolvimento e sustentabilidade: um estudo sobre o programa de cooperação nipo-brasileira para o desenvolvimento dos cerrados (PRODECER). Dissertação (mestrado) - Universidade de Brasília (UnB), Brasília, DF, 1996.

. Programas Agrícolas na Ocupação do Cerrado. Sociedade e Cultura, Goiânia, GO, Universidade Federal de Goiás (UFG), Vol. 3, N. 1-2, Jan-Dez, 2000, pp. 111-131. Disponível em: <http://www.revistas.ufg.br/index.php/fchf/article/view/459>. Acesso em 10 de janeiro de 2017.

PIMENTEL, Helen Ulhôa; BOTELHO, Rosana Ulhôa. Presença nipônica em Paracatu: a nova geração. Narrativas de celebração, produção de conhecimento histórico e alteridade. Anais do XXIV Simpósio Nacional de História-História e multidisciplinaridade: Territórios 
e deslocamentos. São Leopoldo, RS, Associação Nacional de História (ANPUH), 15 a 20 de julho de 2007. Disponível em: <http://anpuh.org/anais/wpcontent/uploads/mp/pdf/ ANPUH.S24.0878.pdf $>$. Acesso em 10 de janeiro de 2017.

ROSTOW, Walt Withman. The stages of economic growth: A non-communist manifesto. Cambridge: Cambridge University Press, 1960.

SAID. Edward. Orientalismo: o Oriente como invenção do Ocidente. São Paulo: Companhia das Letras, 1996.

SAITO, Hiroshi (Org.). A presença japonesa no Brasil. São Paulo: Editora da Universidade de São Paulo (USP), 1980.

SANTOS, Clóvis Caribé Menezes dos. Programa de Cooperação Nipo-Brasileira para o Desenvolvimento dos Cerrados - PRODECER: Um espectro ronda os cerrados brasileiros. Estudos Sociedade e Agricultura, Ano 24, V. 2, outubro de 2016. Disponível em: <http://r1.ufrrj.br/esa/V2/ojs/index.php/esa/article/view/802/454>. Acesso em: 10 de março de 2017.

SANTOS, Rosselvet José. Gaúchos e Mineiros do Cerrado: metamorfoses das diferentes temporalidades e lógicas sociais. Uberlândia, EDUFU, 2008.

SUZUKI, Katsunari. Brasil, Japão e Ásia: passado, presente e futuro. In: GUIMARÃES, Lytton Leite (org.). Ásia - América Latina - Brasil: a construção de parcerias. Brasília: NEÁSIA/ CEAM/UnB, 2003.

TAKEUCHI, Marcia Yumi. A comunidade nipônica e a legitimação de estigmas: o japonês caricaturizado. In: Revista USP, São Paulo, n.79, p. 173-182, set/nov 2008.

. Entre gueixas e samurais: A imigração japonesa nas revistas ilustradas (18971945). Tese (Doutorado) - Universidade de São Paulo, Programa de Pós-Graduação em História Social, 2009.

VANSINA, Jan. La tradición oral. Barcelona: Editorial Labor AS, 1966. 